\title{
THE IMPLEMENTATION \\ OF THE EDUCATIONAL CONSULTATION METHOD IN ARAB SCHOOLS IN ISRAEL FROM THE PERSPECTIVE OF TEACHERS
}

\begin{abstract}
Ramadan S. Izabel, Hadas Routh, The Implementation of the Educational Consultation Method in Arab Schools in Israel from the Perspective of Teachers [Wdrożenie metody konsultacji edukacyjnych w szkołach arabskich w Izraelu z perspektywy nauczycieli]. Studia Edukacyjne nr 40, 2016, Poznań 2016, pp. 421-434. Adam Mickiewicz University Press. ISSN 1233-6688. DOI: 10.14746/se.2016.40.22

The role of the educational counsellor in schools has undergone modification in response to recent changes in social, familial and pupil characteristics. The traditional, one-on-one approach has gradually been replaced with collaborative methods that are more in keeping with the times, more comprehensive and more proactive. One method of collaborative teaming that has increasingly found its way into schools is consultation. This is an indirect intervention process based on interaction between counsellors ("consultants") and teachers ("consultees") where the former provide professional advice, within their fields of specialization, for dealing with specific problems encountered by teachers in their day-to-day work. It is meant to support teachers in dealing with the demanding school environment by primarily working directly with them rather than with pupils and by providing important professional resources and problem-solving skills. My research examined this method from the perspective of teachers in Israeli schools in Nazareth, where the student population and the teachers are Arab. Data were collected using in-depth interviews. Among other things, the results indicated a willingness on the part of teachers to adjust to new methods but pointed to systemic obstacles to effective implementation.
\end{abstract}

Key words: Israel, Arab schools, teachers

\section{Introduction}

The perception of the role of the educational counselor has undergone significant changes in the last two decades. The shift that has taken place 
replaces the traditional, one-on-one approach of educational counseling within the school with methods that are more in keeping with the times, more comprehensive and more proactive. These newer methods are based on an organizational paradigm that incorporates professional collaboration and teaming of professionals in order to meet the growing demand for services from a limited number of professionals who are available to provide counseling.

One method of collaborative teaming that has increasingly found its way into schools is referred to as consultation. This is an indirect intervention process based on interaction between consultants and teachers ("consultees") where the former provide professional advice within their fields of specialization for dealing with specific problems encountered by consultees in their day-to-day- work in the classroom. It is meant to support teachers in dealing with complex problems within the demanding school environment by primarily working directly with them rather than with pupils and by providing them with important professional resources and problem-solving skills.

The research presented in this article examines the consultation method from the perspective of teachers in Israeli schools in the city of Nazareth where the student population and the teachers are Arab. The study group included 15 teachers from 6 different primary and secondary schools. Data from teachers were collected in 2010 using in-depth interviews that included general and open-ended questions as well as targeted items on the following issues:

- Teachers' perceptions of the ways in which the consultation method has been implemented in their school.

- Teachers perceptions of the educational counselor's role.

- Teacher's expectations from the consultation process.

Qualitative data analysis was conducted using in-depth content analysis in an effort to evaluate the extent to which the implementation of consultation methods was successful and contributed to reported satisfaction of teachers with the modified role of the educational counselor.

\section{The consultation method: Previous research}

As early as the 1960s, consultation within the mental health professions was defined as a process of interaction between two professionals: A consultant, who is the expert, and a consultee who is seeking advice on a work 
problem from a professional who is perceived as an expert in the area in which advice is being sought. ${ }^{1}$

Over the years, the definition has been expanded, but two basic characteristics continue to be shared in interventions of this type: 1) The consultation is an indirect service to a third party who is not present at the meeting between consultant and consultee; and 2) The consultation is convened to serve a specific and well-defined purpose: To find a solution to a problem encountered by the consultee regarding the subject of the consultation and associated with the occupational role of the consultee. ${ }^{2}$

In contrast to conventional educational counseling where two parties are involved, (in our case, teacher and student), in the consultation process, there are three parties, but only two are present. The method can be implemented in schools in a variety of ways and in different frameworks. Consultation can be individual in the classic model where the educational counselor or psychologist meets with one of the educators in the school, such as the teacher, and the frequency and nature of the meetings are determined by various factors and conditions within the school system. Consultations can also be with a group of individuals who share the same profession or the same role (teachers; students etc) in order to deal with a common issue.

Group consultation has a number of advantages: The group forum allows for different perspectives on the problem and at the same time empowers its members through the sharing of experiences and advice. In this way, it also reduces dependency on the counselor. ${ }^{3}$ But in both cases, individual and group, consultation as an intervention method has value not only because it is an effective use of the educational counselor's time, but also because it contributes to individual growth and mental health. ${ }^{4}$

\section{The major players}

The educational counselor or advisor is at the heart of the shift from patterns of traditional and individual-centered counseling to system-oriented

\footnotetext{
${ }^{1}$ G. Caplan, Types of mental health consultation in schools, American Journal of Orthopsychiatry, 1963, 33, p. 470.

2 R. Erhard, Empowering consultation: Theory and practice, Tel Aviv 2008, p. 19.

${ }^{3}$ Ibidem; A. Lavid, Consultations with teachers for improving socio-emotional areas, Oranim 2007.

${ }^{4}$ E. Clemens, Developmental counseling and therapy as a model for schoolcounselor consultation with teachers, Professional School Counseling, 2007, 10, 4, p. 352-359.
} 
counseling in schools. In contemporary society in general and Arab society in particular, school-aged children face a complex reality and often conflicted relations within the familial and the social contexts of their lives. This creates an ever-increasing gap between pupils in need of emotional, social and intellectual support and the resources available to respond to the need.

The challenge is to find new and innovative methods that can impact on the school system as a whole rather than on individual pupils on a one-onone basis. The educational consultant is in a position to reach each and every member of the educational staff and provide them with the tools and problem solving skills to more effectively perform their educational roles. ${ }^{5}$

The demands and expectations from the role of educational consultant in Israel are particularly complex and multi-dimensional. Research shows that the nature of the position and the associated goals are defined in different ways by various factors involved in the process: The Ministry of Education, school principals, colleagues and clients. The multiplicity of conflicting demands may put the consultant in a position of filling many simultaneous tasks and roles, including treatment, facilitator, counselor, administrator, mediator, arbitrator and, more recently, consultant. The lack of role boundaries and definitions applies not only to tasks and responsibilities but also to the target population toward which resources are supposed to be directed. It is not clear whether the primary client is the pupil, teacher, parent, school administration or the school system as a whole.

The role of the teacher in contemporary society is also increasingly complex. In addition to the usual classroom issues, teachers today must cope with a variety of behavioral problems and learning disabilities, violence in schools, and a host of other social conflicts that often leave many feeling tired and burnt out as well as frustrated, angry and guilty. ${ }^{6}$

New demands and expectations are continually placed on teachers who, in addition to meeting the intellectual and emotional needs of their pupils, must adjust teaching methods and content to new communication technologies and theories of learning. ${ }^{7}$ Yet classroom conditions and salaries do not

${ }^{5}$ P. Mor, A. Lurie, The power of the educational advisor: The school as a magnified educational environment, Jerusalem 2006.

${ }^{6}$ R. Erhard, Empowering consultation.

7 A. Levi-Feldman, Who are you "worthy" teacher? Education and its EnvironmentYearbook of Kibbutz, Seminar, 2010, p. 87-95. 
always keep pace with changing demands; parents are often unsupportive and motivating pupils is increasingly challenging. ${ }^{8}$

In light of these conditions, evidence thus far shows that both principals and teachers in Israel, as elsewhere, look favorably on the consultation method. ${ }^{9}$ The implementation of models of school-based consultation in other Western countries has been increasingly found to improve outcomes for consultants, consultees and clients alike. ${ }^{10}$ More specifically, the new concept of educational consultant offers support for teachers, opportunities for the educational staff to learn new skills and most importantly empowerment and a way of promoting learning by identifying problems and facilitating solutions.

In the course of the consultation process, the teacher may develop a broader awareness and understanding of problems, whether with a specific pupil, parents, or with the class as a whole. Information and skills provided by the consultant is aimed at improving the capacity to evaluate needs and alternative solutions to social, emotional and learning problems. These are all important tools for meeting complex situations that will undoubtedly arise in daily classroom experiences. ${ }^{11}$

To summarize, the basic players in the consultation process are as follows

- The educational counsellor - who is at the heart of the shift from patterns of traditional and individual-centered counseling to system-oriented counseling in schools. His or her role is to provide the educational staff with knowledge and skills, to empower them and increase their awareness of pupils needs.

- Teachers - who become the intermediaries between consultants and pupils as clients. For the process to be successful, teachers need to believe in

${ }^{8}$ W.P. Erchul, B.K. Martens, School consultation: Conceptual and empirical bases of practice, New York 2002.

${ }^{9}$ W.P. Erchul, S.M. Sheridan, Overview: The state of scientific research in school consultation, [in:] Handbook of research in school consultation, Eds. W.P. Erchul, S.M. Sheridan (2nd ed.), New York 2014, p. 3-17; M. Newell, D.S. Newman, Assessing the state of evidence in consultation training: A review and call to the field, [in:] Handbook of research, p. 421-449; R. Erhard, Empowering consultation; P. Mor, A. Lurie, The power of the educational advisor.

${ }^{10}$ E.C. Lopez, B.K. Nastasi, Process and outcome research in selected models of consultation, [in:] Handbook of research, p. 304-320; S.M. Sheridan, W.P. Erchul, Epilogue: Final comments on school consultation research, [in:] Handbook of research, p. 525-531; A. Lavid, Consultations with teachers.

${ }_{11}$ S.M. Sheridan, W.P. Erchul, Epilogue: Final comments; A. Lavid, Consultations with teachers. 
the professional abilities of the consultant and in their own abilities as problem solvers.

- Parents - must also be taken into account by consultants must take into account as significant factors in the pupils' lives, both facilitating and inhibiting. Parents may be included in meetings with the consultant.

- Pupils are the main clients in the consultation model and all of the efforts between the various players are geared toward improving learning opportunities in the broadest sense of the word.

Despite a wide range of variation, we can point to the following common characteristics of consultation models as described in the literature:

1. This is an indirect service that is not provided directly to the client but rather to a "consultee" on behalf of the client.

2. The consultee initiates the request for assistance and is responsible for the presenting the problem, for implementing a solution and for the wellbeing of the client.

3. The relationship between the consultant and the consultee is based on trust, mutual involvement, cooperation and equality, with no difference in authority or status.

4. The consultant is knowledgeable in the field of mental health and responds to problems that are raised without any attempt to expose other areas where the consultee lacks sufficient knowledge.

5 . The privacy of the consultee is fully respected.

6. The consultee is free to accept or reject the advice from the consultant.

7. The aim of the consultation is to improve the ability of the consultee to cope with a current problem and, at the same time, increase the ability to deal with other professional difficulties in the future.

\section{Arab society and the school climate}

Arab society can be characterized as a society in transition. ${ }^{12}$ Significant changes have taken place as a result of modernization and globalization. These changes are reflected in a rise in educational attainment, improvements in the standard of living, exposure to mass media and technology and the development of a political leadership that is gradually replacing local,

12 R. Khamaisi, Transition from Ruralism to Urbanization: The Case oif Arab Localities in Israel, Horizons in Geography, 2012, p. 168-183; D. Soen, Gender Equality? IJEMS, 2013, 6(2), p. $135-158$. 
traditional authorities. However, as some have argued, changes have taken place primarily at the individual level and have not been translated into institutional and group change (Al-Haj).

At the group level, Arab society continues to be a traditional, patriarchal and male-dominated society where the prevailing cultural orientation is collectivist. ${ }^{13}$ Cultural norms and expectations continue to place priority on a woman's duties toward the home and family. Housework is women's work, thus Arab women in the workforce in general, and teachers in particular, are often under close scrutiny and pressure from the extended family and the community at large to ensure that husbands and families come first. ${ }^{14}$

Within Arab schools and classrooms, which represent a separate educational track within the Israeli public educational system, deeply entrenched cultural values and norms continue to operate, creating a climate that is in many ways different from the traditional Western school. The micro politics of the clan and local authorities in Arab towns and villages are known to have a strong influence on decision making in the school. Often they dictate appointments of school principals and other staff and the climate in the school. ${ }^{15}$ Until recently, for example, there have been very few female principals. ${ }^{16}$ Men still hold the majority of principal positions despite the fact that women are the majority of teachers, at least at the elementary school level.

A recent qualitative study of Arab schools, points to an authoritarian and patriarchal structure and to traditional teaching methods. ${ }^{17}$. Teachers who were interviewed voiced criticism of the lack of transparency and mutual trust between the principals and teachers; principals cited the attitudes of parents, their interactions with the school and with teachers and the lack of parental responsibility concerning their children's behavior.

In addition to the school climate, in the realm of cultural influences, the studies cited above point to traditional teaching methods, such as frontal lectures and lack of student participation or discussion as an obstacle to the

\footnotetext{
13 S. Sagy et al., Individualism and Collectivism in Two Conflicted Societies: Comparing Israeli Jewish and Palestinian Arab High School Students, Youth and Society, 2001, 33(1), p. 3-30.

${ }^{14} \mathrm{~K}$. Arar et al., Arab Women in Management and Leadership: Stories from Israel, New York 2013.

${ }^{15} \mathrm{~K}$. Abu-Baker, Arab Society in Israel: Between exclusion and discrimination or incorporation and equality, Jerusalem 2006.

$16 \mathrm{~K}$. Arar et al., Arab Women in Management and Leadership.

${ }^{17}$ K. Arar, A. Massry-Herzllah, A Motivation to Teach: The Case of Arab Teachers in Israel, Educational Studies 2016, p. 1-18.
} 
educational process and to student achievement in Arab schools. Teachers, it would appear, have not adapted to changes in the educational environment, in particular to technological changes, and have not adjusted teaching methods accordingly. Some related these issues to the personal self-image of teachers, particularly older teachers, to a lack of self-confidence and competence in teaching skills, oversensitivity to criticism and other poor foundations for self-efficacy in the classroom.

Finally, measures of student achievement point to problems in educational outcomes. Abu-Asbah reported in 2012 that over 30 percent of Arab youth fail to complete 12 years of education. Also in 2012, 47 percent of Arab high school students passed the matriculation exam, compared to 60 percent of Jewish students. 18 On standardized international tests administered to high school students in 2009,19 there was a consistent difference of approximately 20 percent in reading comprehension and literacy scores, with differences larger among Arab and Jewish boys compared to girls.

Some of the differences in achievement are undoubtedly attributable to differences in the investment of resources at the national and community levels. However, socio-cultural factors also appear to play a significant role. It is against this background that we turn to a discussion of research conducted in 2010 on the implementation of the consultation method in Arab schools, in the framework of my Master's thesis. Based on previous research and an understanding of contemporary Arab society in Israel, the expectation was that the method would alleviate some of the pressure on teachers and provide them with much-needed support and professional input.

\section{Methodology}

The research described here is based on a qualitative, phenomenological approach aimed at exploring the response of teachers to the consultation method, as implemented in six Arab primary and secondary schools in the town of Nazareth. The major research instrument was a specially designed in-depth interview for teachers based on ten central questions and specific probes for each question. The main questions were:

1. How has the consultation method been implemented in your school?

2. Please describe your relationship with the consultant

18 Jerusalem Post Internet edition December 2012.

${ }^{19}$ S. Swirski, N. Dagan-Bouzaglo, Discrimination, Inequality and Control: The Status Quo of Israeli Education, Tel Aviv 2009. 
3. Who general initiates consultant-consultee meetings?

4. When do you usually turn to the consultant?

(For what kinds of issues?)

5. What is the nature of the discussion at meetings with the consultant?

6. In general are you satisfied with the role of the consultant

7. Can you give an example of a meeting that was helpful to you? (What was helpful?)

8. Can you give an example of a meeting that was problematic? (What was problematic?)

9. What would you like to see changed in the role and performance of the consultant?

10. Is there anything else you would like to add?

Interviews were conducted in Arabic with 15 teachers: eight primary and seven secondary school teachers. With one exception, the sample had all been teaching for seven years or more, with the majority in the teaching profession for over 10 years. The sample included three male teachers and 12 female teachers. The findings reported below are based solely on the perceptions and information provided by teachers themselves and not on other reports on implementation processes.

\section{Major findings}

Implementation of the consultation method. In general, the teachers in the sample reported a wide range of implementation methods; with no one model of consultation dominating over others. Rather, aspects of different models were integrated. Most of the teachers described relatively short, informal meetings with the consultant of 10-15, between classes in the teachers' room, the hallway or the consultant's office, where the emphasis was on some type of "counselling". At the same time, there were also scheduled group meetings on a weekly or monthly basis. Not surprisingly, the latter were perceived as more effective than the short individual meetings. Homeroom teachers were perceived as those who benefitted most from the consultation method. These are teachers who bear the greatest responsibility for the general and emotional well-being of students.

Content of meetings. The topic of most of the meetings, as reported by teachers in the sample, was related to emotional and behavioral issues, particularly those involving families and social networks. More importantly, 
however, was the finding that teachers expressed lack of sufficient skills or knowledge to cope with the issues raised. Thus for example, one of the teachers noticed a regression in the school work of one of her pupils. In her discussion with the pupil, she understood that his mother was undergoing chemotherapy treatment, but felt unprepared to address the issue alone and turned to the consultant for help. Similarly, cases of divorce or death in the family were cited as instances where the consultant had played a role.

One high school teacher related the following example:

"I had a somewhat unusual case of a girl in my class who had attempted suicide. When I sat with the consultant, she had information on the family's background that was helpful in deepening my understanding of the case and how to follow-up with my reporting. Sometimes it's hard to accept that parents can be an obstacle standing in the way of their child."

In many of the cases reported, the consultant helped the teacher to feel empathetic toward specific pupils rather than seeing them as a distraction in the classroom. It appears from what was reported that the three party meetings, with parents present, in many cases helped to reduce the risk and number of dropouts from the system. This in and of itself can be seen as a major achievement.

Perceptions of the consultant's role. Most of the respondents ascribed great significance to the role of the consultant as an important figure in their professional work and their personal lives. They appreciated the support and the opportunity to have someone to talk to about the issues cited and someone who would listen to them. Significantly, they understood the shift in the role of the consultant from direct counseling to pupils and students to indirect assistance through counseling of teachers. One teacher observed:

"There are personal matters that can get in the way of teaching. I had such an experience. A cousin with whom I was very close died at the age of 40 . I took it very hard. I went into a depression. I couldn't sleep. I would explode at things that happened at school. The consultant got me through the period. He listened to me talk about my cousin, what I loved and missed about him. This was a tremendous source of support for me personally."

Another teacher remarked:

"I learned from the consultant not to keep things and feelings inside. This was a very important lesson for me. It helped me be less aggressive because I learned to say what was on my mind before it got out of hand."

Facilitating factors. There was relatively little criticism of consultants by the respondents. To the extent that criticism was voiced, it was directed 
against the educational system and the school and, in particular, the principal. Lack of time for meetings was a key factor that was seen as influencing how well the method was working. The difficult family circumstance of many of the pupils was also stressed. One respondent related:

"We work under very difficult conditions. I have one student who is not only problematic herself, but influences those around her. I met with her and with her parents under the supervision of the consultant and we discussed the risk that she was at of dropping out. This was an important connection between the student, her parents and myself"

Another teacher described the widespread nature of the family problems:

"I have six pupils from broken and non-functioning families. How can I deal with all this? The consultant gives me specific steps to take and this makes it easier."

Consultants also reportedly helped teachers deal with the dilemma of not wanting to get involved in problems where there was a feud between two families or where there were cases of domestic violence that could cause "a mess" if the information got out and came from the school or the teacher. One teacher reported the following:

"I had a case where there was domestic violence in the family. I wanted to report the matter but I was afraid it would cause all sorts of unnecessary problems, especially since we are a traditional society and these subjects are very sensitive."

Level of satisfaction. While the level of satisfaction with individual consultants was high, there was equally high disappointment with the manner in which the consultation was implemented in all of the various schools. The main disappointed derived from the fact that meetings with the consultant were more likely to be random rather than structured into the teachers' schedules. Many sympathized with the heavy work load and time pressures under which consultants worked and this prevented them from raising issues that they saw as important but less urgent relative to others.

Comments from three different teachers are instructive in this respect:

1) "I would like to have more time to discuss my dilemmas, personal feelings and approaches to various cases and not just as quickly as possible describe the problem at hand. Because of the time pressures I put off raising many problems that I know the consultant could help me with if she weren't so busy." 
2) "The school places more emphasis on educational achievements and less on social and psychological change. So, the consultant ends up dealing more with learning issues than with other barriers to well-being among pupils."

3) "The consultant needs to initiate group meetings and not just respond to requests for help from individual teachers. I think her role has the potential to be one of the most significant in the school but the work conditions limit her capacity to be more present and have a greater influence."

\section{Conclusions and recommendations}

The findings from this exploratory study of the educational consultation method are consistent with previous research. The preliminary results point to a positive attitude toward the potential new roles for consultants and to positive results of the method as an intervention model. As such, they support findings from other studies as discussed above.

Teachers were open to the innovations in the method of consultation. The main criticism that they had was leveled at the system for failing to implement and give appropriate priority to a structured consultation program. The weakest link in the chain appears to have been the school principal. But the examples of where the consultants had helped teachers personally and professionally suggest an overwhelming need for the kind of support and direction that they can provide.

The observed need and appreciation for the role of the consultant in many ways stems from the traditional and collective nature of the society in which teachers operate, which makes it difficult for them to discuss underlying issues of a personal or intimate nature. These findings suggest that if properly implemented on a larger scale, the method is likely to be wellreceived and achieve significant improvements not only in teacher-pupil relations but in parent teacher-relations in Arab education as well.

Nonetheless, further research is required on school-based consultation before a large scale program can be put into effect in the Arab sector. In particular, as suggested by Sheridan and Erchul ${ }^{20}$ (2014) in there comprehensive review of the state of research worldwide, more attention needs to be paid to questions of what works for whom and under what conditions? This requires a look at the method from the perspective of clients and consultants and not only consultees; it requires more rigorous research designs that

\footnotetext{
${ }^{20}$ S.M. Sheridan, W.P. Erchul, Epilogue: Final comments on school.
} 
compare one-on-one methods with consultation models, particularly in schools with large populations of youth at risk where teachers face complex problems on a day to day and hour to hour basis.

Finally, more attention needs to be paid to the issue of training for educational consultants and preparatory work within the school system and specific schools. Thus, for example, seminars on the consultation method geared to school principals may help to overcome resistance and to promote a structured program with adequate time allocated to meetings with teachers and other parties in the process.

\section{BIBLIOGRAPHY}

Abu-Asbah K., Education for Values in a Society in Crisis, Massar Institute of Research, Planning and Educational Counseling, Tel Aviv 2012.

Abu-Baker K., Arab Society in Israel: Between exclusion and discrimination or incorporation and equality, The Institute for Israel-Arab Studies, Van Leer, Jerusalem 2006 (Hebrew).

Al-Haj M., Education, Empowerment and Control: The Case of Arabs in Israel, State University of New York, Albany 1995.

Arar K., Massry-Herzllah A., A Motivation to Teach: The Case of Arab Teachers in Israel, Educational Studies 2016.

Arar K., Shapira T., Azaiza F., Hertz L.R., Arab Women in Management and Leadership: Stories from Israel, Palgrave Macmillan, New York 2013.

Caplan G., Types of mental health consultation in schools, American Journal of Orthopsychiatry, $1963,33$.

Clemens E., Developmental counseling and therapy as a model for schoolcounselor consultation with teachers, Professional School Counseling, 2007, 10, 4.

Dahan T., Jerusalem Post, Internet edition, December 2, 2012.

Erchul W.P., Martens B.K., School consultation: Conceptual and empirical bases of practice, Kluwer/Plenum, New York 2002.

Erchul W.P., Sheridan S.M., Overview: The state of scientific research in school consultation, [in:] Handbook of research in school consultation, Eds. W.P. Erchul, S.M. Sheridan (2nd ed.), Routledge, New York 2014.

Erhard R., Empowering consultation: Theory and practice, Ramot, Tel Aviv 2008 (Hebrew).

Jerusalem Post Internet edition December 2012.

Khamaisi R., Transition from Ruralism to Urbanization: The Case oif Arab Localities in Israel, Horizons in Geography, 2012.

Lavid A., Consultations with teachers for improving socio-emotional areas, Masters Thesis, Oranim 2007 (Hebrew).

Levi-Feldman A., Who are you "worthy" teacher? Education and its Environment - Yearbook of Kibbutz, Seminar, 2010 (Hebrew).

Lopez E.C., Nastasi B.K., Process and outcome research in selected models of consultation, [in:] Handbook of research in school consultation (2nd ed.), Eds. W.P. Erchul, S.M. Sheridan, Routledge, New York 2014. 
Mor P., Lurie A., The power of the educational advisor: The school as a magnified educational environment, JDC Ashalim, Jerusalem 2006.

Newell M., Newman D.S., Assessing the state of evidence in consultation training: A review and call to the field, [in:] Handbook of research in school consultation (2nd ed.), Eds. W.P. Erchul, S.M. Sheridan, Routledge, New York 2014.

Sagy S., Orr E., Bar-On D., Awad E., Individualism and Collectivism in Two Conflicted Societies: Comparing Israeli Jewish and Palestinian Arab High School Students, Youth and Society, 2001, 33(1).

Sheridan S.M., Erchul W.P., Epilogue: Final comments on school consultation research, [in:] Handbook of research in school consultation (2nd ed.), Eds. W.P. Erchul, S.M. Sheridan, Routledge, New York 2014.

Soen D., Gender Equality? IJEMS, 2013, 6(2).

Swirski S., Dagan-Bouzaglo N., Discrimination, Inequality and Control: The Status Quo of Israeli Education, Adva Center, Tel Aviv 2009. 